\title{
Un modelo para el análisis cuantitativo y cualitativo del mensaje periodístico en los noticiarios de televisión
}

\author{
Fernando de HARO \\ Universidad Francisco de Vitoria \\ fernando.deharo8@gmail.com
}

Recibido: 18 de diciembre de 2013

Aceptado: 19 de mayo de 2014

\begin{abstract}
Resumen
Este trabajo crea un modelo para el análisis de temas y de significantes de los informativos de televisión. Con ese propósito se desarrollan trece indicadores que cuantifican cuestiones relaciones con la estructura, el contenido, la naturaleza y el uso del lenguaje audiovisual. Para la cuantificación se utilizan la práctica habitual de la televisión informativa. El modelo permite, a través de un sistema numérico, establecer el nivel (alto, medio, bajo) de cada uno de los indicadores.

Palabras clave: Televisión informativa, análisis del mensaje, análisis de contenidos, informativos de TV, noticias

\section{A model for a quantitative and qualitative analysis of the journalist's message in the news program}

\begin{abstract}
This research creates a model for analyzing the news programs' significants and subjects. With this purpose thirteen indicators are developed. This indicators quantify aspects related to structure, content, nature and use of audiovisual language. For this quantification, regular practice of news programs broadcasts are used. This model allows to establish a level (high, medium, low) through a numeric system for each one of the indicators.
\end{abstract}

Keywords: News program broadcast, information analysis, contents' analysis, news program, news

\section{Referencia normalizada}

HARO, Fernando de (2014): "Un modelo para el análisis cuantitativo y cualitativo del mensaje periodístico en los noticiarios de televisión". Estudios sobre el Mensaje Periodístico. Vol. 20, Núm. 2 (juliodiciembre), págs.: 771-787. Madrid, Servicio de Publicaciones de la Universidad Complutense.

Sumario: 1. Introducción: un modelo para el análisis de los informativos de televisión. 2. Metodología. 3. Desarrollo; 3.1. Indicadores de estructura; 3.1.1. Indicador de continuidad; 3.1.2. Indicador de renovación; 3.2. Indicadores de naturaleza; 3.2.1. Indicador de amplitud informativa; 3.2.2. Indicador de volumen; 3.2.3. Indicador de equilibrio; 3.2.4. Indicador de interpretatividad; 3.3. Indicadores audiovisuales; 3.3.1. Indicador de narratividad audiovisual; 3.3.2. Indicador de discursividad audiovisual; 3.3.3. Indicador de inmediatividad; 3.3.4. Indicador de calidad de imágenes; 3.3.5. Indicador de calidad de montaje; 3.3.6. Indicador de calidad de sonido; 3.3.7. Indicador de asociatividad; 3.3.8. Indicador de calidad de grafismo. 4. Conclusiones. 5. Referencias bibliográficas.

\section{Introducción: un modelo para el análisis de los informativos de televisión}

El propósito del presente artículo es intentar desarrollar un modelo de análisis de los informativos de televisión que se encuadra dentro de lo que algunos autores han definido como "un análisis de contenido". Igartua y Humanes (2004), recogiendo las aportaciones de Riffe, Lacy y Fico (1998), lo definen "como un procedimiento que permite asignar de manera sistemática los contenidos de la comunicación a categorías 
utilizando para ello métodos estadísticos" y con el que se examina "científicamente tanto los "significados" (análisis temático) como los "significantes" (análisis de los procedimientos, de las convenciones, de los rasgos formales) de cualquier texto". En este caso hablamos de un texto audiovisual para el que vamos a crear una herramienta de análisis, sobre todo, de sus significantes. No se trata, por tanto, de crear un instrumento para indagar en lo que Casals Carro (1999) denomina la "racionalidad periodística".

Al referirse al análisis de contenido, Wimmer y Dominick (1996: 70) afirman que "es un método de estudio y análisis de comunicación de forma sistemática, objetiva y cuantitativa, con la finalidad de medir determinadas variables". Neuendorf (2002) sostiene que el análisis de contenido es un procedimiento de investigación cuantitativo que permite obtener descripciones sumarias de mensajes muy variados entre los que se incluyen desde mensajes individuales como los de cartas personales hasta los mensajes dirigidos a amplias audiencias. En ellos se pueden identificar toda clase de variables o de indicadores.

\section{Metodología}

Se han realizado trabajos de análisis del contenido de los noticiarios como el de Guerrero Serón (1999), Humanes (2001) o Díaz Arias (2008) que han supuesto una gran aportación al generar indicadores que permiten un cotejo de carácter sociológico. En la misma dirección, con una aportación diacrónica, se encuentra el trabajo de Gutiérrez, Rodríguez Fidalgo y Gallego Santos (2010). Otros trabajos han analizado los contenidos en función de criterios particulares como la calidad en el caso de López Téllez y Cuenca García (2005) o el género el de López Diez (2001).

El modelo que más adelante se describe está basado en aquellos indicadores que nos han parecido más relevantes para analizar el contenido en función de cómo se expresa a través del lenguaje audiovisual. Utilizamos aquí el término lenguaje en un sentido amplio, como lo usaba Walter Benjamin (2007: 144), cuando aseguraba que "toda comunicación de contenidos espirituales es lenguaje, y la comunicación por la palabra no es sino un caso particular [...] así se puede hablar de un lenguaje de la música y de la escultura, de un lenguaje de la justicia y de un lenguaje de la técnica". Solarino (May, 1959: 2012-2013) lo aplica a la televisión cuando sostiene que "la televisión es un medio de comunicación; como tal está caracterizado por un lenguaje propio o específico televisivo, que respeta reglas precisas de gramática o sintaxis".

Intentamos conseguir lo que Igartua y Humanes (2004) denominan "la conceptualización": "identificar las variables que se pretende analizar en los textos y adoptar una definición conceptual precisa de las mismas". Estas variables, indicadores las llamaremos nosotros, son "los aspectos de los mensajes que varían de uno a otro y, por tanto, pueden ser manifiestas o latentes y referirse a aspectos formales o de contenido". Los indicadores se elaboran para aplicarlos a los noticiarios que, en este caso, son las unidades de análisis, lo que Bardin (1986: 81) denomina "la unidad de compresión para codificar la unidad de registro", el "segmento del mensaje cuyo tamaño es óptimo para captar la significación exacta de la unidad de registro". 
De los cinco campos de aplicación de análisis de contenido descritos por Wimmer y Dominick (1996: 172) vamos a generar un modelo para describir los componentes de la información, para poder realizar un análisis descriptivo. Dejamos de lado las relaciones entre las fuentes y el mensaje, la comparación del contenido con el mundo real o la evolución de la imagen de grupos sociales concretos. Este modelo pretende construir una técnica concreta de medida, generando unas categorías de análisis que sean excluyentes entre sí, que tiendan a la exhaustividad, que sean fiables, con un sistema adecuado de cuantificación de los indicadores. Para lograr este último propósito, para llegar a lo que Igartua y Humanes (2004) describen como "el nivel de medida de cada variable", ya que "medir significa atribuir números", hemos optado por una escala ordinal con tres valores: alto, medio y bajo. Esta escala permite la jerarquización de los objetos analizados en función de un criterio.

\section{Desarrollo}

\subsection{Indicadores de estructura}

Nos van a servir para situar los informativos en el conjunto de la emisora

\subsubsection{Indicador de continuidad}

Para medir de qué modo la emisora lleva a cabo una información de carácter continuo sirve de referencia el número de noticiarios u avances que se emiten a lo largo del día y de la semana y el peso proporcional que tienen en la programación. La continuidad se considerará alta si la cadena incluye tres o más noticiarios en la programación diaria, media si incluye dos y baja si incluye solo uno.

\subsubsection{Indicador de renovación}

Este indicador sirve para medir la renovación informativa que lleva a cabo la cadena en la que se emiten los noticiarios, estableciendo una comparación entre los dos noticiarios más próximos en el tiempo. Para fijar el grado de renovación de la información, se toma como referencia el porcentaje de información (entradillas, vídeos, colas y totales) que se repite entre los noticiarios más próximos. Si el porcentaje de información que se repite sin modificación alguna de texto leído o de imágenes es superior al 60 por ciento, la renovación de la información es baja, si la repetición está comprendida entre el 60 y el 30 por ciento se puede considerar que la renovación es media y si el índice de repetición es menor al 30 por ciento se estima que la renovación es alta.

\subsection{Indicadores de naturaleza}

Es necesario que nuestro modelo sea también un herramienta para conocer qué información contienen los esos noticiarios, ese es el propósito de este grupo de indicadores.

\subsubsection{Indicador de amplitud informativa}

Podríamos crear, para analizar cuantitativamente el contenido de los noticiarios, un indicador sobre el número de noticias $\mathrm{y}$, sin duda, sería significativo. Pero hemos preferido desarrollar un primer indicador sobre cuántas cuestiones diferentes son tratadas 
por el noticiario porque eso nos permite conocer mejor lo que hemos denominado la amplitud del noticiario. Para fijar los valores se puede utilizar una ratio que relaciona número de noticias con número de asuntos. Si la ratio es 1-1, la amplitud es alta; si es de 1-2 la amplitud es media; y si es de 1-3, la amplitud es baja.

\subsubsection{Indicador de volumen}

La segunda cuestión cuantitativa relevante es la de cuánto tiempo se dedica a la información dentro de cada informativo. Como más adelante se explica, no todos los elementos de un noticiario son información, toda vez que existen elementos de continuidad o de publicidad. El objetivo de este indicador es determinar el tiempo real que el noticiario dedica a la información, excluyendo titulares, espacios publicitarios, cortinillas y transiciones. Tomamos como referencia el trabajo realizado por León Gross (2007: 274) sobre el volumen informativo de los noticiarios españoles de ámbito nacional para considerar que el volumen es alto si el tiempo real informativo es de más de 30 minutos tienen un volumen alto, que es medio si cuenta con entre 20 y 30 minutos de información y que es bajo si tiene menos de 20 minutos de volumen de información.

\subsubsection{Indicador de equilibrio}

Después de los indicadores cuantitativos de naturaleza es necesario seleccionar algunos indicadores cualitativos que puedan aportarnos datos sobre el tipo de información de los noticiarios. El primer indicador de este campo es el indicador de equilibrio. Es un indicador que nos ayudará a responder la pregunta: ¿qué tipo de información emiten los noticiarios y qué tiempo asignan a cada tipo de información? Y también a la cuestión de si la distribución del tiempo entre los diferentes tipos de información es equilibrada. Se ha identificado el equilibrio con el modo en el que distribuyen el tiempo, entre los diferentes tipos de información, los noticiarios nacionales españoles.

Elaborado a base del minutado de los noticiarios, este indicador nos puede servir para hacer una valoración cuantitativa del tiempo que ocupan las diferentes secciones siempre y cuando el noticiario sea de carácter nacional. Como referencia pueden tomarse también los datos del estudio realizado por León Gross (2007: 275), las noticias del periodismo de referencia (que incluye internacional, nacional, economía y cultura) representan el 55,2 por ciento y la de periodismo popular (espectáculos, deporte y sucesos) el 44,7 por ciento. Y podemos establecer que un noticiario de ámbito nacional es: altamente equilibrado si la información de referencia supera el 55 por ciento; medianamente equilibrado si la información de referencia está en el 35 y el 55 por ciento; bajamente equilibrado si la información de referencia está por debajo del 35 por ciento.

\subsubsection{Indicador de interpretatividad}

Analizar la naturaleza de la información de los noticiarios exige hacerlo en función del tratamiento de que ha sido objeto, por el contenido seleccionado. Podemos hacerlo con este indicador de interpretatividad para responder a la siguiente pregunta: ¿se ofrecen de ella claves interpretativas adecuadas? Este indicador tiene como objeto medir el peso que los géneros más analíticos tienen en la escaleta de los noticiarios para faci- 
litar la interpretación de la información. Consideraremos como géneros analíticos la entrevista realizada en plató o fuera de él, en la que se recaba la opinión de un experto o de un protagonista de la información. También se considerará un género analítico el reportaje en el que sobre una cuestión se ofrezcan diferentes puntos de vista o información relevante de los antecedentes y las consecuencias de la noticia. Se puede considerar que un noticiario tiene alta interpretatividad cuando recurra a los géneros analíticos en más de un caso, media cuando recurra a los géneros analíticos en un caso y baja cuando no recurre a ningún género analítico.

\subsection{Indicadores audiovisuales}

Este modelo debe poder servir para analizar también cómo se ha tratado la información desde el punto formal, cómo se ha utilizado el "lenguaje audiovisual" en sentido estricto.

\subsubsection{Indicador de narratividad audiovisual}

Dado que vamos a analizar si el uso del lenguaje audiovisual es el adecuado, una de las cuestiones más relevantes es precisar si las formas posibles que existen para producir y emitir una noticia se han utilizado pertinentemente. Hemos recurrido a la expresión "forma" aunque otros autores como Oliva y Sitja (1996: 120) prefieren hablar de "formato de la noticia" y Cebrián (1998: 210) de "modalidades". Con la intención de analizar si esas formas, que se describen más adelante, se han utilizado correctamente se crea el indicador de narratividad. Es un indicador que nos servirá para responder a la pregunta: ¿en qué medida se han utilizado las formas adecuadas propias de la noticia televisiva?

La información en televisión tiene su propia gramática, unas formas de la lingüística audiovisual pensadas para expresar los diferentes contenidos informativos. Rodríguez Pastoriza (2003: 58 y ss.) recoge algunas de estas formas. Siguiendo su trabajo y las aportaciones realizadas por Cebrián (1998: 252) se puede hacer la siguiente descripción que fija características y funciones:

- Noticia a cámara que consiste en la lectura del texto de la noticia por parte del presentador. "Es la menos frecuente de las estructuras que puede adoptar la noticia y únicamente se utiliza cuando la noticia se considera lo suficientemente importante para no dejar de emitirla, pero no se dispone de imágenes".

- Noticia con conexión en directo. "Diálogo del presentador del programa informativo con un corresponsal o enviado especial al lugar de la noticia". Es una forma que tiene sentido cuando la presencia del periodista, bien por razones de imagen $\mathrm{o}$ de contenido informativo, añade valor. A menudo se utiliza como recurso narrativo para aumentar la sensación de inmediatividad informativa sin que por ello la información sea más completa. La progresiva consideración de los noticiarios televisivos como un espectáculo ha incrementado, a pesar del alto coste de las conexiones en directo, este tipo de noticias. Cebrián (1998: 253) asegura en este sentido que "a veces se emplea el directo como alarde tecnológico por la emisora sin aportar información alguna. Es más si se suprimiese el directo, la información no perdería nada". 
- Noticia en colas. La noticia la "lee en su totalidad uno de los presentadores [...]" y se cubre "con imágenes y sonido ambiente. Habitualmente el presentador aparece durante los primeros segundos, aunque en otros casos sólo se escucha su voz". Esta forma está pensada para noticias no muy importantes o para noticias que han seguido abiertas hasta poco antes de la emisión del noticiario.

- Noticia en Videotape Recording o noticia en vídeo. Se trata de "una pieza montada previamente a su emisión, que consiste en un montaje de imágenes que ilustran el texto leído por una voz en "off". Suelen incluir las declaraciones de los protagonistas y los stand up de los periodistas. Se debe utilizar para noticias relevantes, contadas con intervenciones de personajes significativos y con un argumento.

- Noticia en forma de total. El presentador da paso a las declaraciones de un protagonista de la noticia desde plató. Esta forma debe utilizarse para contar noticias en las que lo único noticiable es la declaración.

Existen algunas formas más pero todas derivan de las mencionadas. El indicador de narratividad audiovisual nos va a servir para saber si las formas se han utilizado de modo adecuado. Si sólo un 10 por ciento de las formas se ha utilizado de un modo inadecuado, podemos hablar de una alta narratividad audiovisual alto, si se han utilizado de un modo inadecuado entre un 10 y un 30 por ciento hablaremos de una narratividad media y si se han utilizado mal más de un 30 por ciento hablaremos de una narratividad audiovisual baja.

\subsubsection{Indicador de discursividad audiovisual}

Además de saber si las "formas" propias de la noticia televisiva han sido utilizadas adecuadamente, necesitaremos una herramienta que sirva para evaluar cómo se ha construido el conjunto del discurso. Con este fin hemos desarrollado el indicador de discursividad que nos permitirá estudiar la relación entre los diferentes bloques propios de un noticiario y la relación entre las noticias.

Un noticiario no debe considerarse como un conjunto aislado de noticias sino como un discurso audiovisual completo. La construcción del discurso-noticiario requiere una adecuada distribución de sus elementos y una relación entre esos elementos que sea equilibrada. Como señala Cebrián (2004), "existe el montaje de la noticia, el montaje del bloque y, en suma, el montaje o secuencialidad del telediario en su conjunto [...], dentro de esta narrativa hay que situar la narración de noticias y de bloques en un telediario". En la construcción del discurso-noticiario es determinante la ordenación jerárquica de las noticias. Aunque la estructura de la pirámide invertida, referente para la información escrita, no es una regla absoluta en la información audiovisual, sí es determinante para la construcción del discurso la noticia y la imagen con la que se comienza. La guerra de audiencias ha provocado que, en muchos casos, la noticia de apertura no sea la más relevante. En muchos casos se decide en función de las imágenes más llamativas aunque esas imágenes tengan un escaso valor informativo. En cualquier caso, el presente índice no pretende valorar la jerarquización informativa. La coherencia interna viene dada, en gran medida, por la coherencia entre los diferentes bloques informativos y por la coherencia dentro de los bloques. "Normalmente las 
noticias son agrupadas por bloques. Esto permite una mejor contextualización y ubicación de los hecho". Dentro de los bloques de noticias destacan el bloque de sumario y el bloque de cierre.

El bloque de sumario es definido por Cebrián como "anticipación de los contenidos sobresalientes del programa [...] índice ordenado de las noticias que se desarrollan posteriormente, [...] marco sucesivo" (Cebrián, 2004: 484). Rodríguez Pastoriza (2003: 58 y ss.) lo define como "presentación sucinta de las principales noticias que se incluyen en la edición"; y Saperas y Grife como "presentación sucinta de las noticias principales de la actualidad del día o del momento de la edición, que proporciona el eje argumentativo central al noticiario" (1995). Estos dos últimos autores, concluyen que "todos los informativos de la muestra (una muestra europea) incluyen sumario, con una sola excepción". El noticiario con un sumario más amplio incluía diez noticias y lo habitual eran cuatro. Pero quizás lo más significativo de esta investigación, es que había una relación entre el bloque del sumario y la estructura del noticiario: "la relación entre unidades en sumario y tiempo total del noticiario dedicado al desarrollo de tales noticias ofrece una coincidencia muy alta en todas la cadenas". Hay buena discursividad audiovisual si la estructura del bloque del sumario, incluidas las noticias de apertura que no se reflejan en los titulares, son proporcionalmente desarrollas en la escaleta.

Junto al bloque del sumario otro con fuerte personalidad es el bloque de cierre. Hay muchas fórmulas: en algunos casos se repite el sumario -una práctica cada vez más en desuso- y en otras se selecciona una noticia relajada o con imágenes de alto valor estético. La opción por un tipo u otro de cierre no nos da un mayor índice de discursividad. Cualquier tipo de cierre implica que se ha querido concluir el discurso, por el contrario, la falta de un bloque de cierre diferenciado indica que no se ha construido bien el discurso. Además de analizar los bloques de apertura y de cierre, es necesario precisar si los bloques recogen todo la información sobre una cuestión o si la información sobre un mismo tema se dispersa en los diferentes bloques. De igual modo, es necesario analizar la estructura dentro de cada uno de los bloques para precisar si el discurso está enlazado.

Como apunta Cebrián (2004: 486), “dentro de los bloques hay que referirse a las transiciones entre noticias. Son transiciones realizadas generalmente por salto directo desde el final de la noticia hasta la presencia en pantalla del presentador general en plano medio que enuncia directamente, sin ninguna otra introducción, la noticia siguiente". Esa descripción de la transición es precisamente la que podemos denominar de baja discursividad porque en el guión del presentador no se han buscado las conexiones entre una noticia y otra para construir un discurso unitario. Si existen conexiones entre una noticia y la siguiente, el presentador debe hacerlas explicitas y si no existen una relación lógica siempre es conveniente buscar conexiones de proximidad semántica, geográfica o de otro tipo que le permitan al espectador escuchar y ver un discurso engarzado y no elementos sueltos. En ocasiones la búsqueda de esas conexiones entre noticias se fuerza excesivamente de modo que el discurso sufre. Teniendo en cuenta todo lo expuesto se puede establecer como elementos cuantificables de discursividad: 
Coherencia del bloque de sumario con la estructura de la escaleta. Si existe una coherencia alta asignaremos el valor de 3 puntos, si la coherencia es media de 2 puntos y si es baja de 1 .

Concentración o dispersión informativa. Si los bloques informativos contienen toda la información sobre un tema podemos establecer una concentración alta con 2 puntos y si hay dispersión con más de una noticia fuera de su bloque una puntuación de 0 puntos

Transición entre noticias buena con tres puntos. Transición entre noticias media con 2 puntos y sin transición 0 puntos.

Cierre 2 puntos, ausencia de cierre 0 puntos.

Con las puntuaciones asignadas, podemos precisar que el índice de discursividad audiovisual es alto si está entre 9 y 12 puntos, es medio si está entre 5 y 9 puntos y es bajo si es inferior a 5 puntos.

\subsubsection{Indicador de inmediatividad}

Para conocer si el lenguaje audiovisual ha sido utilizado adecuadamente, además de analizar el uso de las "formas informativas" y del discurso, hay que poder analizar las características y el uso que se ha dado a las imágenes. Hemos seleccionado tres características relacionadas con las imágenes que hemos considerado las más relevantes. La primera de ellas se refiere a la relación entre las imágenes y el hecho que reflejan. Cuando Gortari (1969: 16) examina la especificidad del lenguaje televisivo, concluye que es el carácter simultaneo lo que le diferencia, "casi al tiempo, todo el mundo, actor y espectador, se convierten en participes. Es aquí donde se puede decir que la televisión tiene personalidad propia y es el avanzado de la cultura de imágenes". En la misma dirección Violette Morin (1974: 9) afirma que "como las noticias filmadas, la prensa moderna se esfuerza cada día en dar al lector la ilusión de que descubra el acontecimiento en el mismo momento en el que se produce". Sin entrar en valorar si necesariamente la transmisión en directo de las noticias es sinónimo de mejor información, éste puede ser considerado el rasgo más relevante cuando se está estudiando televisión informativa. La información televisiva debe estar lo más próxima posible al acontecimiento noticioso. Como dice Rodríguez Pastoriza (2003: 58 y ss.), "el objetivo ya no es hacernos comprender una situación sino hacernos testigo de ella".

Podríamos establecer, teniendo en cuenta la estructura y forma de la noticia, 4 grados de inmediatividad. Para clasificar las noticias utilizamos como valor de inmediatividad las imágenes usadas para elaborar esas noticias. La clasificación que utilizan García Nebreda, Menor Sendra y Perales Albert (1985) es una buena referencia. Según estos autores hay "dos grandes grupos de imágenes: las mediadoras, en las que no se nos muestra el acontecimiento, ni sus elementos constitutivos, ni imágenes similares, sino que se nos "cuenta" dicho acontecimiento. Y las referenciales cuya característica esencial es tener como referente genérico o estricto al acontecimiento, manteniendo, por tanto, una relación motivada (o de arbitrariedad relativa) con éste".

Con este referente se pueden establecer los siguientes grados de inmediatividad:

- Primer grado. El que confiere la utilización del directo para hacer llegar la noticia o el que confiere la conexión con un corresponsal. 
- Segundo grado. Aunque no se establezca una conexión en directo para transmitir el acontecimiento noticioso o para recabar el testimonio del corresponsal, el periodista ha estado presente en el lugar en el que se ha producido y deja testimonio de ello. Es lo que se denomina una entradilla, medianilla o salidilla. Rodríguez Pastoriza lo denomina genéricamente stand up: "es la presencia de la imagen del periodista en el transcurso de la noticia, contando a cámara alguno de sus aspectos. Conviene que esta presencia se relacione con el lugar de los hechos que se cuentan [...] A través del stand-up se transmite a la audiencia el mensaje de que el periodista ha estado allí y, por lo tanto, tiene información de primera mano".

- Tercer grado. Ni se ha transmitido en directo la noticia, ni se conecta con un corresponsal ni hay stand up, pero se cuenta con imágenes del hecho del que se informa.

- Cuarto grado. Para contar la noticia se utilizan imágenes de archivo metonímicas, imágenes del día que muestran alguno de los elementos del acontecimiento pero siempre fuera del contexto de dicho acontecimiento. Por ejemplo, si el presidente del Gobierno ha participado en un acto por la mañana que ha sido noticia y se ofrecen imágenes de un acto en el que ha participado por la tarde.

- Quinto grado. Para contar la noticia se utilizan imágenes simbólicas, aquéllas cuya semejanza con el referente se impone por convención aceptada, o ambientales, aquéllas que tienen una relación de analogía física o conceptual con el acontecimiento y que lo ilustran por la asociación de ideas-. Ejemplo del primer caso es la ilustración de la información sobre el IPC con imágenes de un mercado y del segundo la ilustración de los datos de una encuesta con imágenes de personas andando por la calle.

Para concretar el grado de inmediatividad, utilizando los anteriores referentes podemos establecer los siguientes porcentajes: si más del 30 por ciento del tiempo informativo se encuentra en un primer grado, la inmediatividad es alta; si el 80 por ciento del tiempo informativo se encuentra entre el primer y el tercer grado, a inmediatividad es media; y si más del 20 por ciento se encuentra entre el cuarto y el quinto grado, la inmediatividad es baja.

\subsubsection{Indicador de calidad de imágenes}

Además del grado de inmediatividad se debe examinar la calidad de las imágenes. Este indicador no solo servirá para analizar la corrección de las imágenes emitidas por la calidad de la señal y su resolución. También intentará precisar si los tipos de encuadres y de planos, así como los movimientos de la cámara realizados, son los adecuados para la narración informativa que se quiere realizar. Como ha señalado Barroso García (1992: 343-386), la utilización de determinados encuadres y planos guía la mirada del espectador sobre la realidad de la que se informa y marca el punto de vista objetivo o subjetivo del espectador. "El plano -asegura Cebrián (2004: 486) - plasma la noticia, configura la expresión del hecho [...] La información televisiva tiene como objetivo ser lo más fielmente posible a lo que ha ocurrido. Se observa a veces una tendencia a composiciones demasiado esteticistas que expresan una gran imaginación o creatividad, pero escasa información de los hechos. Tales tratamientos tienen validez en los reportajes y aquellos programas o formas de expresión que admitan mayor libertad". Para cuantificar el índice se tendrán en cuenta los siguientes elementos: 
- Adecuado nivel de crominancia y luminancia. Como explica Solarino (2000: 22), "en la cámara a color se generan tres señales, una por cada uno de los colores primarios [...] las tres señales relativas a los tres colores vienen codificadas oportunamente de manera que se produzca una señal idéntica a la de blanco y negro, luminancia, y otra señal de informaciones de color, crominancia". Cuando los niveles de crominancia y de luminancia son los correctos, se obtiene una buena señal.

- Adecuada resolución de la imagen que "es el parámetro que establece la nitidez o definición [...] se expresa por el número máximo de puntos que aparecen separados a lo largo de una línea de longitud preestablecida. La resolución televisiva, además de expresar la nitidez de imagen, representa un parámetro fundamental de valoración de calidad de los equipamientos" (Solarino, 2000: 25).

- Adecuada relación señal-ruido. También explica Solarino que "cada dispositivo electrónico produce una perturbación llamada ruido [...], en los sistemas de vídeo se manifiesta como un conjunto de pequeños puntos de movimiento casual o nieve [...] La nieve que puede aparecer en la pantalla televisiva no depende sólo del dispositivo de reproducción sino de toda la cadena de aparatos que le preceden" (Solarino, 2000: 27) Consideramos que cualquier nivel de ruido es inadecuado.

- Adecuado encuadre del presentador/es. Rodríguez Pastoriza (2003: 58 y ss.) observa que "un 96 por ciento de los planos referidos a los conductores de los telediarios utilizan una distancia media que corresponden al primer plano y al plano medio, que consiguen esa mirada frontal gracias a la que el presentador busca la confianza de un espectador que no forma parte de la narración [...] la mirada a los ojos quiere transmitir garantía de realidad, aval de veracidad de lo que se transmite". La discusión en torno a la conveniencia de utilizar para los presentadores primeros planos o planos medios largos o planos medios cortos ha sido larga entre los especialistas. Hay quien ha argumentado que los planos medios y los planos medios cortos son "invasivos" para el espectador y no permiten la suficiente objetividad. En realidad, los planos medios cortos y los primeros planos se han acabado imponiendo. Para evaluar si el plano de los presentadores es el adecuado no se entrará en la opción más o menos intimista que se ha hecho del encuadre sino en el carácter informativo de ese encuadre y en la coherencia que guarda con el resto del noticiario.

- Adecuada utilización del tipo de plano para la información que se está ofreciendo. Utilizando como referencia de los tipos de planos la nomenclatura recogida por Borras y Colomer (1977: 135), se valorará si han sido correctamente utilizados. Si en los 5 elementos enumerados, la imagen responde a los criterios de adecuación se considerará que el indicador es de calidad alta, si responde en 4 se considerará calidad media y si responde a menos de 4 , de baja calidad.

\subsubsection{Indicador de calidad de montaje}

Examinada la calidad de cada una de las imágenes en solitario, será necesario analizar si la secuencialidad que se establece entre ellas es correcta. Rodríguez Pastoriza (2003: 58 y ss.) define el montaje como "la operación de organizar el conjunto de planos y tomas de una obra audiovisual en función de un orden prefijado [...]; es el principio que rige la organización de los elementos fílmicos visuales y sonoros [...] articula 
una selección de espacios y tiempos para crear una narración y un ritmo adecuados para la comprensión del mensaje". El montaje de una noticia, como indica Green (1973: 111-114), es el que crea la estructura definitiva de la narración. Con él, según Cebrián (2004) se "establece el orden, la secuencialidad de las imágenes en función del relato informativo concebido de manera global y en relación con la expresión oral. Borrás y Colomer (1977: 135) establecen tres tipos de montaje: el montaje continuo en el que los planos conservan la unidad espacio-temporal y su unión tiene una función estrictamente narrativa; el montaje discontinuo en la que se rompe "la unidad espacio- tiempo porque se efectúa una síntesis mediante la eliminación de una parte de la acción que se considera accesoria”, lo que genera una relación elíptica entre los planos; y por fin el montaje ideológico en el que desaparece el valor narrativo. Las reglas de estos tres tipos de montaje son universales, aunque se aplican de un modo diferente cuando se está haciendo cine y televisión; cuando se hace televisión informativa y cuando se hace televisión de ficción. En el cine y en la televisión de ficción se utilizan imágenes que se han grabado conforme a un guión, y en la televisión informativa se utilizan imágenes que se han grabado sin un guión o que han grabado personas con las que no se trabaja. De hecho, muchas veces el debate en la televisión informativa se limita, como señalan Robinson y Levy (1986: 205) a si hay que montar primero las imágenes y después encajar en ellas la locución o si hay que grabar primero el texto y luego montar las imágenes. Unos argumentan que la palabra debe estar subordinada a la imagen y otros que la televisión informativa debe primar. Son dos opciones que no incluiremos en este indicador. Enumeramos una serie de reglas de buen montaje que si se cumple, indicarán calidad:

- No repetición de un mismo plano ni en la misma noticia ni en todo el informativo analizado

- Respeto del raccord, definido por Borras y Colomer (1977: 146) como la "concordancia cromática de la imagen, su coherencia tonal [...] la coordinación que debe existir entre los planos para no romper la ilusión de que se está viviendo una acción continuada".

- Coherencia en el montaje discontinuo de acciones sin unidad temporal y espacial, recurriendo para ello a fórmulas de elipsis.

- Respeto de los ejes.

- Duración adecuada de los planos. El uso establece que los planos que se utilizan para hacer televisión informativa deben durar entre 2 segundos y 5 segundos.

- No enlace de planos en movimiento.

- Ritmo coherente. Si se opta por un montaje rápido con numerosos planos de escasa duración o por un montaje lento, con menos planos de más duración, la opción debe mantenerse dentro de toda la noticia o dentro de parte de la noticia.

- Construcción de secuencias con coherencia temática. Las imágenes informativas no están destinadas a cubrir los textos y el montaje es de más calidad cuando construye secuencias agrupadas temáticamente.

- Extensión adecuada de las noticias. El montaje de las noticias que se considera conveniente es de 20 segundos como máximo para un total, 30 segundos como máximo para unas colas, entre un minuto y dos minutos para un vídeo. 
- Correcto corte y montaje de las declaraciones y totales.

Si se respetan entre 10 y 7 de las reglas enumeradas podemos hablar de un indicador alto de calidad de montaje, si se respetan entre 5 y 7 la calidad es media y si se respetan menos de 5, la calidad es baja.

\subsubsection{Indicador de calidad de sonido}

Junto a las imágenes el otro elemento decisivo del lenguaje audiovisual es el sonido. Como señalan Alcalde y Reyes (2005), "en la forma audiovisual se produce una articulación entre el sonido y la imagen, es decir, surge un sentido desde el orden preciso en que ambos se han reunido". Y precisamente lo que llama la atención en la nueva televisión es que "prevalece la condición de canales, el sonoro y el visual, menos articulados, a veces vacíos, incluso contradictorios, pero exigidos por la praxis actual comunicativa y constitutivos del nuevo concepto audiovisual, desde cualquier producto televisivo a los videojuegos y los teléfonos móviles". Este indicador no solo detalla las características técnicas sino que evalúa si su uso ha sido el más adecuado para el propósito informativo.

La calidad de sonido no solo viene dada por la claridad y precisión con la que llega al espectador sino por el valor informativo que adquiere en la narratividad audiovisual. Como en otros indicadores, formulamos varias reglas que nos pueden servir para cuantificar la calidad del sonido:

- Nitidez y claridad del sonido.

- Coherencia de las variaciones de volumen.

- Sincronismo técnico que Cebrián (2004: 364) define como "la coincidencia entre los movimientos de los labios y los sonidos de las palabras que se pronuncian".

- Sincronismo objetivo directo utilizado para responder a las necesidades informativas. El sincronismo objetivo directo es la presencia en pantalla de la fuente que está produciendo el sonido que escuchamos. Este sincronismo objetivo directo se debe respetar, por su valor informativo, cuando las declaraciones que se han efectuado son especialmente relevantes o cuando la noticias es un suceso también sonoro.

- Adecuado reflejo del llamado sonido ambiente. Aunque una noticia se dé en colas o en un vídeo, debe incorporar el sonido.

- Locución correcta. Consideramos correcta una locución no por su valor expresivo o narrativo sino por la ausencia de errores de dicción.

- Uso adecuado de la música. Rodríguez Pastoriza (2003: 62) señala que "en ocasiones se recurre a añadir música a determinadas informaciones, con el fin de producir efectos dramáticos o estéticos". Un uso excesivo de la música supone una distorsión informativa.

Si respetan 8 o 7 de estas reglas la calidad del sonido es alta; si se respetan entre 6 y 5 , la calidad es media; y si se respetan menos de 5 la calidad es baja.

\subsubsection{Indicador de asociatividad}

El lenguaje televisivo es un lenguaje de doble codificación, utiliza dos códigos: el texto escrito (que es leído) y las imágenes. La teoría de la doble codificación, des- 
arrollada por Robinson y Levy (1986) explica que imágenes y texto deben conjugarse de forma armónica para producir una percepción asociada en el espectador. Si las imágenes no tienen nada que ver con el texto pierden la capacidad de captar la atención y se requiere un esfuerzo extraordinario para descodificar la información verbal, esfuerzo que no se suele realizar. A este fenómeno Cebrián (2004: 206) lo denomina antisincronía, consecuencia de la "presencia simultánea de imágenes y sonidos con mala conjugación [...] se trata de unas relaciones contradictorias entre los sistemas expresivos [...]. La antisincronía informativa genera dos o más mensajes simultáneos en contradicción porque cada uno ofrece mensajes diferentes [...]. El telespectador se encuentra confundido. Sin embargo, el mayor atractivo de la imagen reclamará su atención y será lo que se imponga a la noticia". No se respeta la doble codificación cuando se escriben textos que no tienen nada que ver con las imágenes o cuando los textos son meramente descriptivos de lo que se ve en las imágenes. Se respeta la doble codificación cuando el texto está pensado para las imágenes; cuando la narración está marcada y limitada por las imágenes; cuando no se repite en el texto lo que se ve y cuando se explica en el texto lo que las imágenes no dicen o no dejan claro.

Se considerará que un noticiario tiene un índice alto de asociatividad cuando más del 60 por ciento de las noticias reflejen una adecuada relación entre imágenes y texto; se considerará un índice medio cuando la relación adecuada se registra en un porcentaje de noticias comprendido entre el 30 y el 60 por ciento y el índice será bajo cuando el porcentaje sea inferior al 30 por ciento.

\subsubsection{Indicador de calidad de grafismo}

Para fijar este indicador utilizamos un concepto amplio de grafismo que incluye tanto lo que Cebrián (2004: 206) denomina "recursos alfanuméricos e iconos generados por ordenador para expresar visualmente determinados contenidos", como las caretas y las ráfagas que sirven para identificar el noticiario. Merrit (1998) ha destacado el valor informativo del grafismo en sentido estricto, que no es una mera ilustración sino un componente expresivo que puede tener autonomía y además integrarse como otro sistema más en el conjunto audiovisual.

El grafismo tradicional está muy ligado a la escritura, la letra escrita se utiliza en los sumarios y titulares; para realizar resúmenes o esquemas de noticias complejas; para identificar a los presentadores, reporteros o corresponsales; para identificar a las personalidades que aparecen en pantalla; para las localizaciones (lugar y fecha del; para dar información sobre el tipo de imágenes que se están utilizando (directo, archivo, etc); y para subtitular declaraciones en otros idiomas. Podemos denominar a este grafismo como grafismo de escritura. El desarrollo de las tecnologías ha permitido el desarrollo de un nuevo grafismo de imágenes fijas o en movimiento, de dibujos lineales o de volumen completo, representaciones, columnas, "tartas", animaciones, mapas de tres volúmenes, etc. Podemos denominar a este grafismo como grafismo de representación.

Y hay un tercer elemento, el de caretas y ráfagas, al que podríamos denominar elemento de identificación. Saperas y Grifeu (1995) en su estudio sobre el formato de la información en las televisiones europeas aseguran que "en un contexto de amplia plu- 
ralidad de ofertas, el reconocimiento instantáneo de la careta de presentación no es sólo una exigencia de marketing, sino también de reconocimiento del formato informativo. La careta tiende a incorporar y presentar en unos instantes las indicaciones de formato del noticiario y de marca (el canal de TV)". Las televisiones europeas que analizaron los autores del estudio solían utilizar para elaborar las caretas "profusión de recursos de animación electrónica e infográfica [...], todos los elementos del lenguaje audiovisual confluyen al unísono para realzar este paso". Entre los elementos más habituales de la careta se encuentran el logotipo del noticiario que no reproduce forzosamente las siglas de la cadena, pero alude a la misma de alguna forma; la sintonía; la indicación horaria, utilizada por la mitad de los noticiarios; y también, en la mitad de los noticiarios, una alusión al globo terráqueo.

Medir la calidad del grafismo de escritura, del grafismo de representación y de los elementos de identificación no es fácil. Hay que fijar parámetros objetivos. En el caso del grafismo de escritura hemos fijado 10 características, atendiendo a su naturaleza y a la función que cumple. Estas características son:

- letras de fácil lectura

- letras con una posición en la pantalla proporcionada al conjunto de la imagen

- tiempo de permanencia en la pantalla adecuado para la lectura

- sumarios convenientemente rotulados

- presentadores y periodistas convenientemente rotulados

- localizaciones convenientemente realizadas en un lugar apropiado de la pantalla

- imágenes en directo convenientemente indicadas

- informaciones complejas convenientemente acompañadas de grafismo

- tipos, cuerpos y colores de letras utilizadas a lo largo del noticiario, coherentes entre sí

- mensajes escritos fácilmente comprensibles.

Si en un noticiario se dan entre 7 y 10 características podemos decir que el grafismo de escritura tiene alta calidad, le asignaremos 3 puntos; si se dan entre 5 y 7 características la calidad es media, le asignaremos 2 puntos; si se dan menos de 5 la calidad es baja no se le asignará puntuación.

En el caso de grafismo de representación la valoración es aún más compleja dado el desarrollo que se ha producido en el mismo. Para cuantificarlo de algún modo podemos considerar que en este apartado la calidad es alta si se utilizan en algún momento imágenes de animación en tres dimensiones para ilustrar alguna información y le asignaremos 3 puntos; la calidad es media si se recurre a otros elementos sin tres dimensiones y la puntuación será de 2 puntos; y la calidad será baja si no se utiliza grafismo de representación, por lo que no se obtendrá puntuación. En el caso de los elementos de identificación, también la valoración cuantitativa es complicada. Podemos enumerar 7 características y atribuirle la máxima puntuación si se cumplen todas ellas:

- existe careta y ráfagas que diferencian al noticiario del resto de la programación y los diferentes bloques

- la imagen de la careta y de las ráfagas es coherente; los elementos de identificación son coherentes con la imagen del conjunto de la cadena 
- la sonorización de imágenes y caretas es correcta y diferenciada; la careta es coherente con el estilo del noticiario

- la careta y las ráfagas son coherentes con el plató

- los elementos de identificación utilizan las nuevas tecnologías de diseño.

Si se dan entre 7 y 6 características se asignan 3 puntos; si se dan 5 o 4 características, 2 puntos; si se dan menos de 4, 0. Podemos considerar que, en total, la calidad de grafismo es alta si se obtienen entre 9 y 8 puntos, que es media si se obtienen entre 7 y 6 y baja si son 6 o menos.

\section{Conclusiones}

Hemos intentado desarrollar un modelo de análisis del contenido de los informativos de televisión, entendiendo por contenido la estructura -relación con el conjunto de la programación-, la naturaleza de la información y el uso del lenguaje audiovisual en sentido estricto. El objetivo era transformar una cuestión cualitativa como es el uso de significados y significantes del lenguaje audiovisual en los informativos de televisión en un modelo cuantitativo. Para generar parámetros cuantitativos se han utilizado dos fórmulas: bien los estudios previos sobre la utilización de ese lenguaje en cada uno de los elementos analizados o bien lo que se ha considerado un uso normal. El propósito se ha logrado al generar 13 indicadores (continuidad, renovación, amplitud informativa, volumen, equilibrio, interpretatividad, narratividad audiovisual, discursividad audiovisual, inmediatividad, calidad de la imagen, calidad del montaje, asociatividad, calidad del grafismo) suficientemente razonados. El debate en torno a estos indicadores y su aplicación posterior pueden convertirlos en una herramienta metodológica para estudiar los informativos de televisión.

\section{Referencias bibliográficas}

ALCALDE, Jesús y REYES, Javier (2005): "De la forma audiovisual a la fórmula multimedia. La plurinformación televisiva". En: Revista Telos. Enero-marzo, núm. 62, $2^{\mathrm{a}}$ época. En: http://telos.fundaciontelefonica.com/telos/articulocuaderno .asp@idarticulo=3\&rev=62.htm

BARDIN, Lawrence (1986): Análisis de contenido. Madrid, Akal.

BARROSO GARCÍA, Jaime (1992): Proceso de la información de actualidad en televisión. Madrid, IORTV.

BENJAMIN, Walter (2007): Obras. Libro II/Vol I. Madrid, Abada Editores

BIAGI, Shirley (1987): Newstalk. Belmont, Wadswoerth.

BORRAS, Jesús y COLOMER, Antoni (1977): El lenguaje básico del film. Barcelona, Nido.

BOURDIEU, Pierre (1998): Sobre la televisión. Madrid, Anagrama.

BUSTAMANTE, Enrique (Coord., 2002): Comunicación y Cultura en la era digital. Barcelona, Gedisa. 
CASALS CARRO, María Jesús (1999): "El arte de la realidad, prospectivas sobre la racionalidad periodística". Estudios sobre el mensaje periodístico, vol. 5, pp. 3762. Madrid, Servicio de Publicaciones de la Universidad Complutense.

CASTAÑARES, Wenceslao (1997): "La televisión y sus géneros, ¿una teoría imposible?". CIC, vol. 3. http://www.ucm.es/info/per3/cic/cic3.htm

CEBRIÁN HERREROS, Mariano (1978): Introducción al lenguaje de la televisión. Una perspectiva semiótica. Madrid, Pirámide.

CEBRIÁN HERREROS, Mariano (1998): Información Televisiva. Madrid, Síntesis.

CEBRIÁN HERREROS, Mariano (2004): La información en televisión: obsesión mercantil y política. Barcelona, Gedisa.

DÍAZ ARIAS. Rafael (2008): "La representación del mundo en los informativos de televisión". Estudios sobre el mensaje periodístico, vol, 14, pp. 363-384. Madrid, Servicio de Publicaciones de la Universidad Complutense.

FOMBONA, Javier (1997): "Análisis objetivo de los mensajes televisivos". Comunicación y pedagogía: Nuevas tecnologías y recursos didácticos, núm. 142, pp. 1016.

FOMBONA, Javier (1998): "La televisión informativa: creatividad comedida". Creatividad polivalente, pp. 411-412. Madrid, UNED.

GARCÍA NEBREDA, Begoña; MENOR SENDRA, Juan; y PERALES ALBERT, Alejandro (1985): “Telediarios. Las malas noticias como coartada del poder". Revista Telos Núm. 2, abril-junio, pp. 44-51.

GORTARI DRETS, Carlos (1969): "Especificidad del lenguaje televisivo". Cuadernos de Televisión, vol. 1. Madrid, Perfeccionamiento de Personal de Televisión.

GREEN, Maury (1973): Periodismo en TV. Buenos Aires, Troquel.

GROUPE $\mu$ (VV.AA., 1995): Tratado del signo visual: para una retórica de la imagen. Madrid, Cátedra.

GUERRERO SERÓN. Carlos A. (1999): "Contenido y audiencia de los informativos: Canal Sur TV y TVE en Andalucía. Una aproximación metodológica". Revista Latina de Comunicación Social, núm. 15 (publicación digital): http://www.ull.es /publicaciones/latina/a1999c/119guerrero.htm

GUTIÉRREZ, Begoña; RODRÍGUEZ FIDALGO, Maribel; y GALLEGO SANTOS, $\mathrm{M}^{\mathrm{a}}$ del Camino (2010): "El tratamiento de las noticias a debate". Revista Latina de Comunicación Social, núm. 65, en: http://www.revistalatinacs.org/10/art/888_Salamanca/10_Begona_Gutierrez_et_al.html

HUMANES, María Luisa (2001): "El encuadre mediático de la realidad social. Un análisis de los contenidos informativos en televisión". Zer, Revista de Estudios de Comunicación. Noviembre, vol. 6, núm. 11, pp. 119-142.

IGARTUA Juan José y HUMANES María Luisa (2004): "El método científico aplicado a la investigación en comunicación social”. Aula Abierta, Barcelona, UAB: http://www.portalcomunicacion.com/download/6.pdf 
LEÓN GROSS, Teodoro (2007): "La agenda de los noticiarios". Tendencias 2006. Medios de Comunicación. El año de la Televisión. Madrid, Telefónica.

LÓPEZ DÍEZ, Pilar (dir., 2001): Representación de género en los informativos de radio y televisión. Madrid, IORTV.

LÓPEZ TÉLLEZ, Antonio y CUENCA GARCIA, Francisco (2005): “Televisión e información: análisis de los criterios de televisión de calidad en los informativos de las cadenas nacionales". Comunicar. Revista cientifica iberoamericana de comunicación y educación. Número 25, en: http://rabida.uhu.es/dspace/bitstream /handle/10272/7041/Televisi\%c3\%b3n_e_informaci\%c3\%b3n.pdf?sequence $=2$

MAY, Renato (1959): Cine y televisión. Madrid, Rialp.

MERRIT, Douglas (1988): Grafismo electrónico en televisión: del lápiz al píxel. Barcelona, Gustavo Gili.

MILLERSON, Gerald (2001): Realización y producción en televisión. Madrid, IORTV.

MORIN, Violette (1974): Tratamiento periodístico de la información. Barcelona, Ate.

NEUENDORF, Kimberly (2002): The content analysis guidebook. Thousand Oaks, Sage.

OLIVA, Llusia y SITJA, Xavier (1996): Las noticias en televisión. Madrid, IORTV.

RIFFE, Daniel; LACI, Stephen; \& FICO, Frederick G. (1998): Analyzing media messages: Using quantitative content analysis in research. Mahwah, NJ, Lawrence Erlbaum Associates.

RODRÍGUEZ PASTORIZA, Francisco (2003): La Mirada en el cristal: la información en televisión. Madrid, Fragua.

ROBINSON, John P. \& LEVY, Mark R. (1986): The Main Source: Learning from Television News. London, Sage.

SAPERAS, Enric y GRIFE, Josep (1995): "El formato de la información en las televisiones europeas. Elementos comunes y peculiariedades significativas" Telos. Núm. 42, junio- agosto, en: http://telos.fundaciontelefonica.com/telos/anteriores/num_042/opi_perspectivas4.html

SEVERIN, Werner J. \& TANKARD, James W. (1991): Communication theories: origins, methods, and uses in the mass media. New York, Longman.

SIERRA BRAVO, Restituto (1983): Ciencias sociales. Epistemología, lógica y metodología. Teoría y ejercicios. Madrid, Paraninfo.

SOLARINO, Carlo (2000): Cómo hacer televisión. Madrid, Cátedra.

WIMMER, Roger D. y DOMINICK, Joseph R. (1996): La investigación cientifica de los medios de comunicación. Una Introducción a sus métodos. Barcelona, Bosch. 
